\title{
A New Method for Start-up of Isolated Boost Converters Using Magnetic- and Winding- Integration
}

Lindberg-Poulsen, Kristian; Ouyang, Ziwei; Sen, Gökhan; Andersen, Michael A. E.

Published in:

Annual IEEE Applied Power Electronics Conference and Exposition

Link to article, DOI:

10.1109/APEC.2012.6165841

Publication date:

2012

Link back to DTU Orbit

Citation (APA):

Lindberg-Poulsen, K., Ouyang, Z., Sen, G., \& Andersen, M. A. E. (2012). A New Method for Start-up of Isolated Boost Converters Using Magnetic- and Winding-Integration. In Annual IEEE Applied Power Electronics

Conference and Exposition: Proceedings (pp. 340-345). IEEE. https://doi.org/10.1109/APEC.2012.6165841

\section{General rights}

Copyright and moral rights for the publications made accessible in the public portal are retained by the authors and/or other copyright owners and it is a condition of accessing publications that users recognise and abide by the legal requirements associated with these rights.

- Users may download and print one copy of any publication from the public portal for the purpose of private study or research.

- You may not further distribute the material or use it for any profit-making activity or commercial gain

- You may freely distribute the URL identifying the publication in the public portal 


\section{A New Method for Start-up of Isolated Boost Converters Using Magnetic- and Winding-Integration}

\author{
Kristian Lindberg-Poulsen \\ Technical University of \\ Denmark, Dept. of \\ Electrical Engineering \\ k.lindberg.p@gmail.com
}

\author{
Ziwei Ouyang \\ Technical University of \\ Denmark, Dept. of \\ Electrical Engineering \\ zo@elektro.dtu.dk
}

\author{
Gökhan Sen \\ Technical University of \\ Denmark, Dept. of \\ Electrical Engineering \\ gs@elektro.dtu.dk
}

\author{
Michael A.E. Andersen \\ Technical University of \\ Denmark, Dept. of \\ Electrical Engineering \\ ma@elektro.dtu.dk
}

\begin{abstract}
A new solution to the start-up and low output voltage operation of isolated boost family converters is presented. By the use of integrated magnetics and winding integration, the transformer secondary winding is re-used during start-up as a flyback winding coupled to the boost inductor. The traditional added flyback winding coupled to the boost inductor is thus eliminated from the circuit, bringing substantial cost savings, increased efficiency and simplified design. Each subinterval of the converter operation is described through electrical and magnetic circuit diagrams, and the concept is extended to other isolated boost family topologies. The principle of operation is demonstrated with a $800 \mathrm{~W}$ isolated boost prototype, and a $1600 \mathrm{~W}$ primary parallel series secondary isolated boost converter. Efficiency measurements of both prototypes are presented, including measurements during both start-up and normal boost operation.
\end{abstract}

\section{INTRODUCTION}

Isolated boost converters have been shown to be the most efficient topology for high power, low input voltage, high output voltage applications [1]-[5]. Suitable applications include distributed generation systems, backup systems, fuel cell converters, electric vehicle applications and avionic applications. However, a disadvantage of the topology is that the boost characteristic sets a lower limit for the output voltage, which introduces in-rush current during start-up from zero output voltage, as well as during fault situations such as output short circuit.

Fig.1 shows a common solution to the start-up problem [6], [7]. A flyback winding is arranged on the boost inductor, such

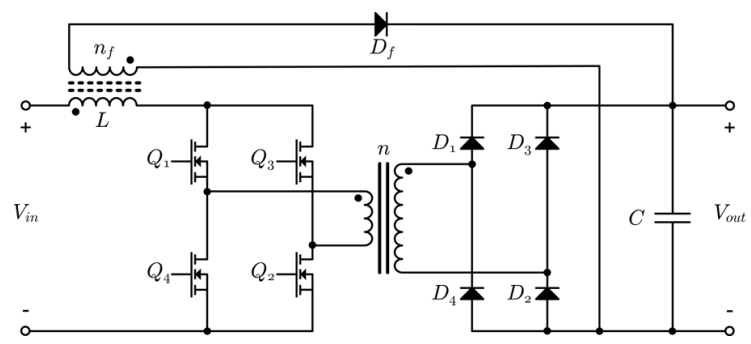

Fig. 1. Isolated full-bridge boost converter with traditional start-up method using added external flyback winding and diode. that the converter may operate as a flyback converter during start-up with the associated buck-boost voltage modulation factor allowing control of the output voltage all the way down to zero volts. During normal boost operation, the flyback winding is completely inactive, but occupies part of the winding window of the boost inductor, leaving less copper area for the boost inductor, which in turn causes a drop in efficiency. Being a power transferring magnetic component, the flyback winding is a relatively expensive circuit element and complicates the assembly of the boost inductor. Fig. 2 and Fig. 3 respectively show the simplified and complete circuit diagrams of the new circuit topology, where the magnetic integration of the boost inductor with the transformer allows the boost inductor to couple to the secondary winding during start-up, such that the secondary winding acts as flyback winding.

\section{PRINCIPLE OF OPERATION}

Figures 4 to 7 explain the principle of operation as applied to the basic full-bridge isolated boost topology. Each

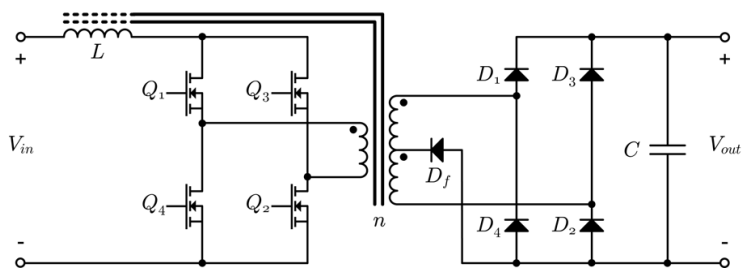

Fig. 2. Electrical circuit diagram of new start-up method.

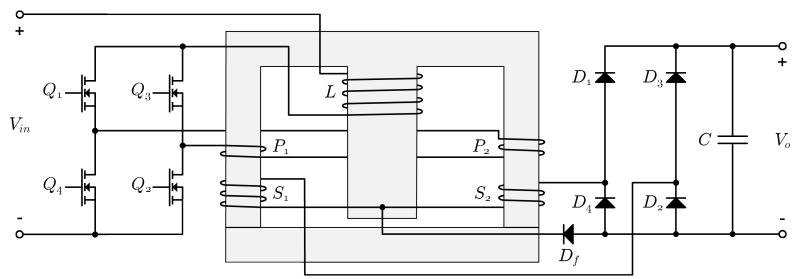

Fig. 3. Electrical and magnetic circuit diagram of new start-up method using EI core with center leg air gap. 
subinterval of operation is shown with an electric circuit diagram followed by the corresponding and a magnetic core diagram. Relevant voltage polarities are marked with +/signs, and current directions are marked with arrows while inactive elements are dimmed. The electric circuit diagrams correspond to their respective core diagrams by the ports marked $a, b, c, d$. The core diagrams include the flux rate, $\frac{d \phi}{d t}=\phi^{\prime}$, induced by the inductor, as well as the flux rate induced by the transformer. The circuit operation can be understood by analysing voltage polarities and flux rates together with the right hand rule, while taking into account the switch states, current directions and diode bias.

\section{Boost mode operation $\left(D_{s w} \geq 0.5\right)$}

In the familiar isolated boost topology, the full-bridge switch duty cycle must be above 0.5 , such that there is always a current path available for the boost inductor. This is defined as the normal boost mode operation. The gate signal is phase-shifted $180^{\circ}$ between each diagonal high-side/low-side switch pair. Since $D_{s w} \geq 0.5$, the phase shifted gate signals overlap such that either all switches are on, or two diagonal switches are on.

When all switches are on, $V_{\text {in }}$ is applied to the boost inductor, and the input current is increasing. Known as the charging or boosting subinterval, the circuit operation during this is shown in fig. 4. As seen in fig. 4(b), the flux rate induced by the inductor is uncoupled from the transformer windings due to the fact that the voltage drops induced on the transformer windings on each side leg are of opposite polarity.

The second sub-interval, referred to as the boost mode discharge subinterval, is shown in fig. 5. When two diagonal switches are on and the other two are off, the inductor current passes through the primary winding, allowing the corresponding diagonal diode pair of the output rectifier to become forward biased. The output voltage is reflected to the primary winding, such that a negative voltage drop is applied over the inductor, decreasing the current. The corresponding core diagram in fig. 5(b) shows that the inductor flux rate is decreasing, and is still uncoupled from the transformer. Additionally, it is noted that the flyback diode $D_{f}$ is reverse biased.

\section{Start-up mode operation $\left(D_{s w}<0.5\right)$}

When the switch duty cycle is reduced below 0.5 , the diagonal switch pairs are no longer overlapping in on-state, meaning that either two diagonal switches are on or all switches are off. When two switches are on, the circuit operation is identical to the boost mode discharge subinterval, except that the inductor current is now decreasing due to the fact that the primary voltage is lower than the input voltage, causing a positive voltage drop over $L$. Because of this, the subinterval is referred to as the start-up mode charging subinterval, and the corresponding circuit and core diagrams are seen in fig. 6 .

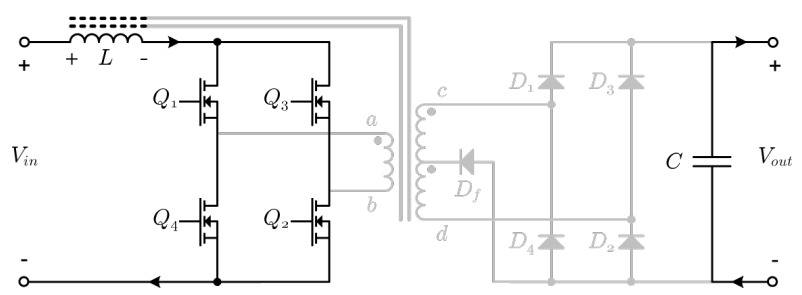

(a) Boost mode, charging subinterval, circuit diagram.

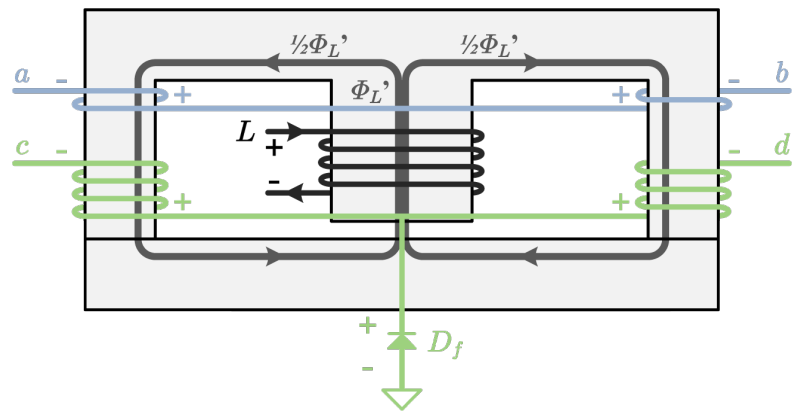

(b) Boost mode, charging subinterval, core diagram.

Fig. 4. Boost mode, charging subinterval. All switches are on, inductor current is increasing. Core diagram shows that inductor flux rate is decoupled from transformer.

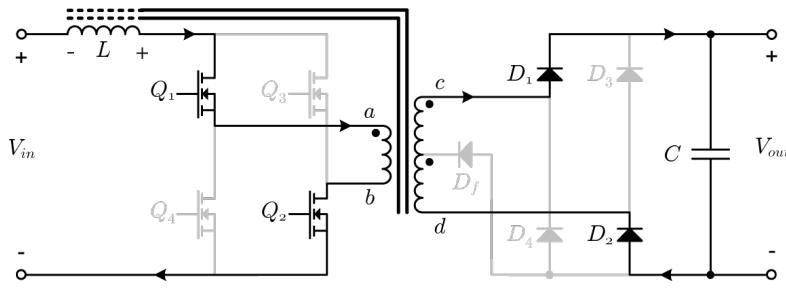

(a) Boost mode, discharging subinterval, circuit diagram.

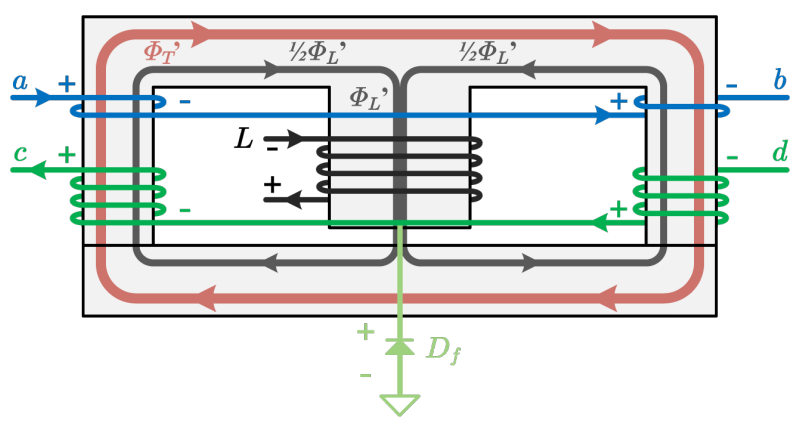

(b) Boost mode, discharging subinterval, core diagram.

Fig. 5. Boost mode, discharge subinterval. Two diagonal switches are on, inductor current is decreased by transferring energy through the transformer. It is noted that $D_{f}$ is reverse biased..

When all switches are off, there needs to be an alternative current path such that the inductor flux remains continuous in order to avoid MOSFET avalanche mode clamping of the stored energy. This current path is provided by the secondary transformer winding, which thereby acts as a flyback winding during the flyback discharge subinterval seen in fig. 7. During switch turn off, the inductor current is decreasing, creating a 


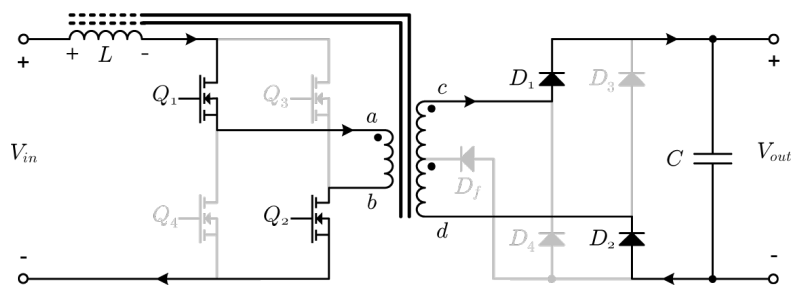

(a) Startup mode, charging subinterval, circuit diagram.

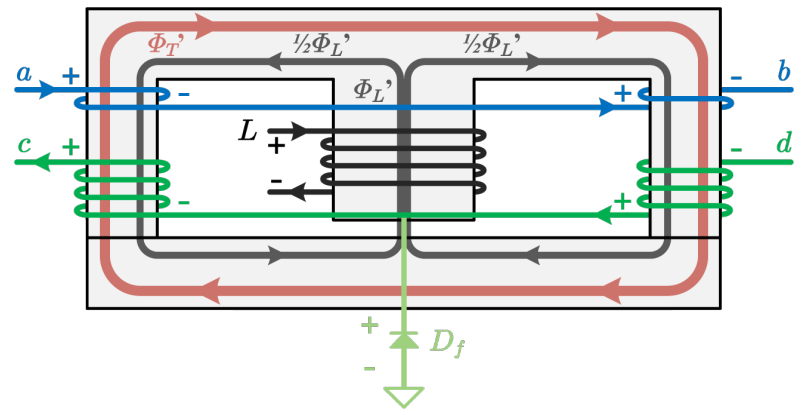

(b) Startup mode, charging subinterval, core diagram.

Fig. 6. Start-up mode, charging subinterval. Two diagonal switches are on, charging the inductor while also transferring energy through the transformer.

reverse in the flux rate, as seen by comparing $\phi_{L}^{\prime}$ on fig. 6(b) and fig. 7(b). Following the right hand rule, it is evident that this induces respective voltage drops over each half of the secondary winding, with polarities such as to allow $D_{f}$ to become forward biased. The two halves of the secondary winding will then be working in parallel to discharge the energy stored in the air gap, with the full output voltage applied to each winding half.

It should be noted that it would also be possible to run the converter in "pure flyback mode", wherein either all switches are on or all switches are off. However, this means that zero energy is transferred to the output during the boosting subinterval, leading to higher current ripple at same output power. The "hybrid" startup mode shown in figs. 6 and 7 has been described in-depth as applied to a conventional external flyback winding [7], and the specific timing analysis of the previous work can be directly applied to the new integrated magnetic approach.

\section{EXTENSION TO OTHER ISOLATED BOOST FAMILY TOPOLOGIES}

The concept can readily be applied to numerous isolated boost derived topologies, such as flyback- current-fed pushpull [8], dual inductor [9], and parallel primary isolated boost [3]. It can also be applied to various rectification circuits, including voltage doubler and center tap rectifier. Figure 8 shows the principle applied to an isolated boost converter with a center tap rectifier. In this case, the flyback diode $D_{f}$ is no longer required, and the start-up functionality is gained "or free" using only the specified integrated magnetic structure, which may be beneficial in itself by reducing magnetic com-

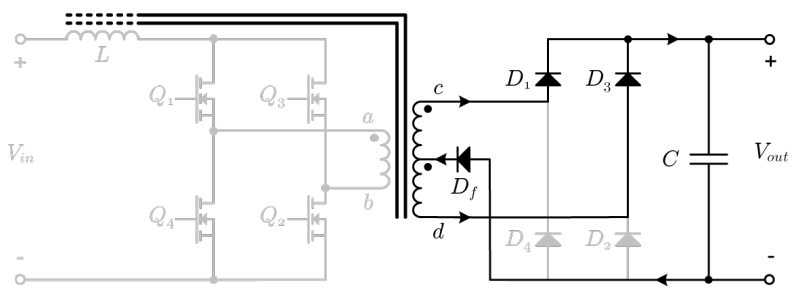

(a) Startup mode, discharging subinterval, circuit diagram.

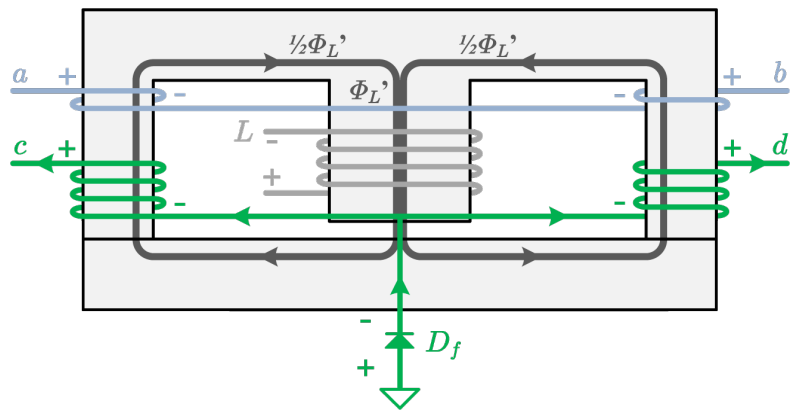

(b) Startup mode, discharging subinterval, core diagram.

Fig. 7. Start-up mode, flyback discharge subinterval. All switches are turned off. The drop in inductor current causes a reverse in the associated flux rate, which couples to the secondary transformer windings. From the polarity of the induced voltages, it is evident that this allows $D_{f}$ to be forward biased, such that the energy stored in the air gap can be discharged to the converter output.

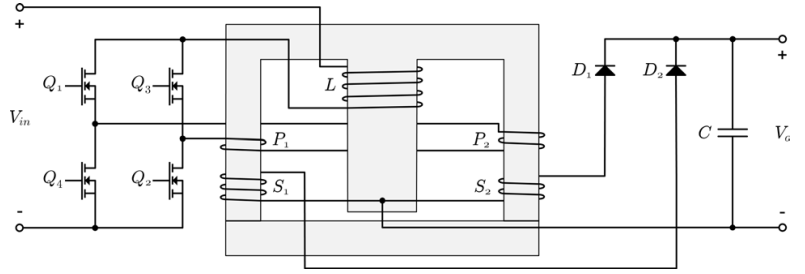

Fig. 8. New start-up method applied to isolated boost with center tap rectification circuit, where a flyback diode is not required.

ponent count and increasing efficiency [10]. Figure 9 shows the principle applied to the parallel primary topology, which has been shown to be an efficient way of scaling isolated boost converter design for higher power [3], [4]. Additionally, the shown implementation features a shared center leg for flux cancellation, resulting in increased efficiency [11]. It is noted that only a single flyback diode is required, regardless of the degree of paralleling.

Additional applications include dual inductor isolated boost and Weinberg/push-pull isolated boost topologies.

\section{EXPERIMENTAL VERIFICATION}

An $800 \mathrm{~W}$ isolated boost prototype as well as a $1600 \mathrm{~W}$ parallel primary isolated boost prototype have been built in order to verify the start-up functionality, as well as to demonstrate the possibility of achieving high efficiency and high power density by application of the integration method. Both converters are hard-switched, and rely on extensive interleaving to achieve a low transformer leakage inductance 


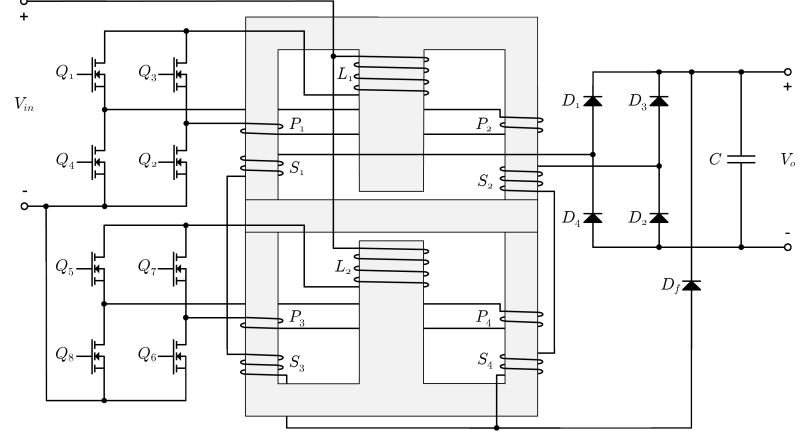

Fig. 9. New start-up method applied to parallel primary isolated boost topology.

of $91 \mathrm{nH}$ and $124 \mathrm{nH}$ respectively. The converters are designed for fuel-cell application, where a fuel cell output voltage of $25-35 \mathrm{~V}$ is expected.

Figure 11 shows current measurements during start-up mode of the isolated boost prototype. The converter is running at $V_{\text {in }}=25 \mathrm{~V}, D_{\text {sw }}=40 \%, V_{\text {out }}=60 \mathrm{~V}$ and $100 \Omega$ load. C3 (blue) shows the AC component of the input current, $\mathrm{C} 4$ (green) shows the AC component of the current through a high side output rectifier $D_{1}$, while $\mathrm{C} 1$ (yellow) and $\mathrm{C}$ (red) show the two gate signals.

When the gate signal $\mathrm{C} 1$ (yellow) is high, $D_{1}$ and $D_{3}$ are forward biased, conducting a constant current through the secondary winding to the load. During this period, the boost inductor current $\mathrm{C} 3$ (blue) is rising. After $\mathrm{C} 1$ (yellow) goes to zero, all MOSFETs are turned off, and the boost inductor current quickly drops. At this moment, current continues flowing through $D_{1}$, safely discharging the energy stored in the boost inductor to the output. In fig. 11, C4(green) shows the current of the flyback diode $D_{f}$, clearly demonstrating the commutation of the boost inductor current.

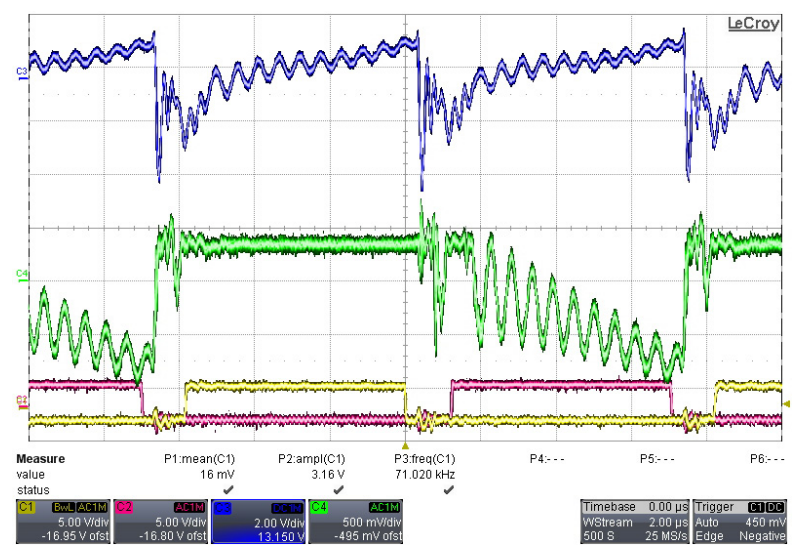

Fig. 10. Currrent waveforms of isolated boost prototype during startup mode. $\mathrm{C} 3$ (blue) shows the $\mathrm{AC}$ component of the input current, $\mathrm{C} 4$ (green) shows the current through a high side output rectifier $D_{1}$, while $\mathrm{C} 1$ (yellow) and C2(red) show the two gate signals.

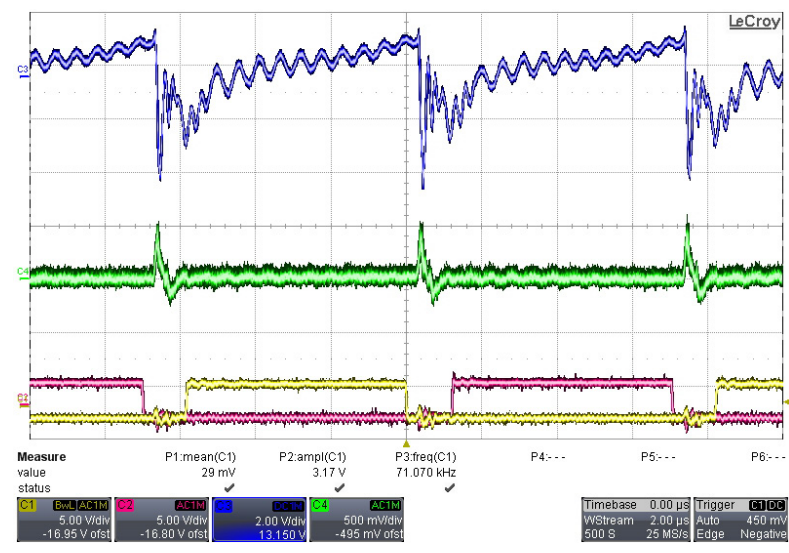

Fig. 11. Currrent waveforms of isolated boost prototype during startup mode. C3 (blue) shows the AC component of the input current, C4(green) shows the current through the flyback diode $D_{f}$, while $\mathrm{C} 1$ (yellow) and $\mathrm{C} 2$ (red) show the two gate signals.

\section{A. Efficiency Measurements}

In order to measure the efficiency during start-up of the parallel primary prototype, the duty-cycle was gradually increased from zero to $74 \%$. A fixed load of $100 \Omega$ is used across the range, corresponding to the rated $1600 \mathrm{~W}$ at $V_{\text {out }}=400 \mathrm{~V}$. Figure 12 shows the resulting efficiency measurements, as well as the measured output voltage at each duty cycle. The local maximum of efficiency around $D_{s w}=20 \%$ is caused by discontinuous conduction mode. Close to $D_{s w}=50 \%$, the efficiency rises dramatically, as an increasingly greater proportion of the total power is transferred through the transformer rather than the flyback operation. The converter is capable of operating continuously in start-up mode without overheating, and the voltage transitions smoothly across $D_{s w}=50 \%$.

The efficiency during normal operation was measured for both the $800 \mathrm{~W}$ isolated boost prototype and the $1600 \mathrm{~W}$ parallel primary. Figure 13 shows the isolated boost prototype measurements, while fig. 12 shows the results for the parallel primary prototype. Both prototypes have a peak efficiency

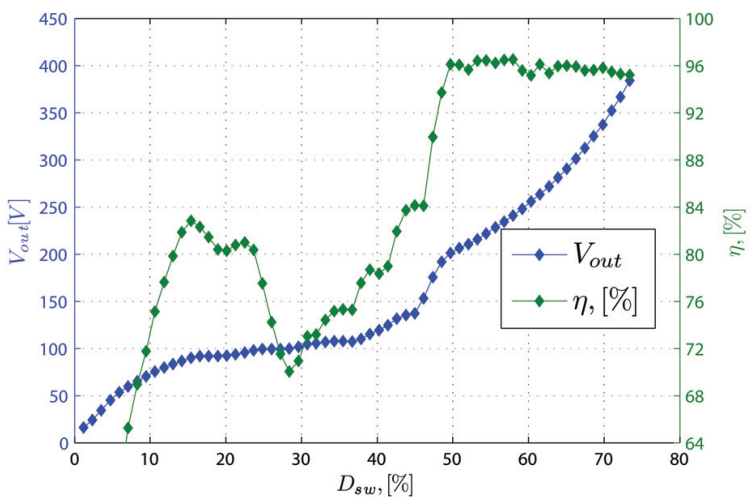

Fig. 12. Efficiency measurements of parallel primary prototype, showing efficiency and output voltage as a function of duty cycle, with a fixed load of $100 \Omega$. 
above $96 \%$ at the rated power, thus demonstrating the possibility of achieving high efficiency with the presented integration method.

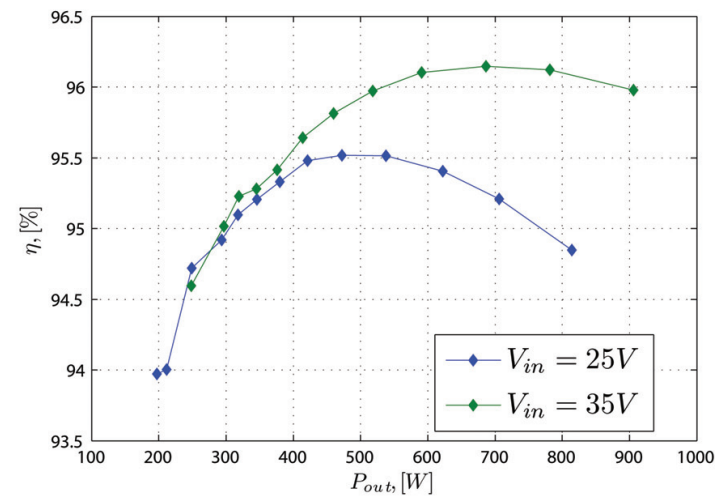

Fig. 13. Efficiency measurements of $800 \mathrm{~W}$ isolated boost prototype, showing efficiency as a function of output power, with $V_{\text {out }}=200 \mathrm{~V}$.

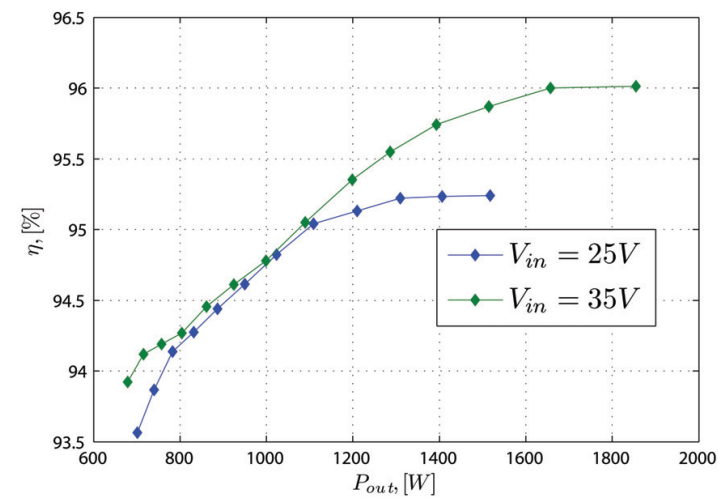

Fig. 14. Efficiency measurements of $1600 \mathrm{~W}$ isolated boost prototype, showing efficiency as a function of output power, with $V_{\text {out }}=400 \mathrm{~V}$.

The parallel primary prototype is shown in fig. 15 and the circuit layout is visible in fig. 16, showing the underside of the converter with the heat sink removed. The parallel primary prototype uses two 6 ounce/sq.ft. copper, 8 layer PCBs, with the two fullbridges mounted directly to each primary winding to minimize stray inductance. A power density of $51 \mathrm{~W} / \mathrm{inch}^{3}$ was achieved, in a low profile planar layout suitable for modular configuration.

\section{CONCLUSION}

The presented start-up method effectively addresses the start-up issue of isolated boost converters, potentially paving the way for increased industry adoption of this highly promising topology family, which so far has been limited by the startup issue. The experimental work presented has focused on fuel cell applications in the $\mathrm{kW}$ power range, but the method may be applied to multiple other applications. The constructed prototypes are hard-switched, and the fly-back mode is not

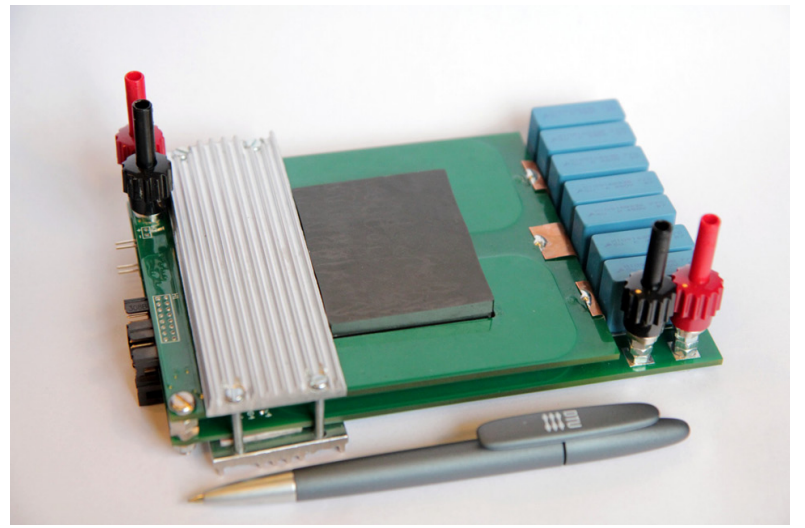

Fig. 15. Parallel primary $1600 \mathrm{~W}$ prototype, achieving a power density of 51 W/inch ${ }^{3}$.

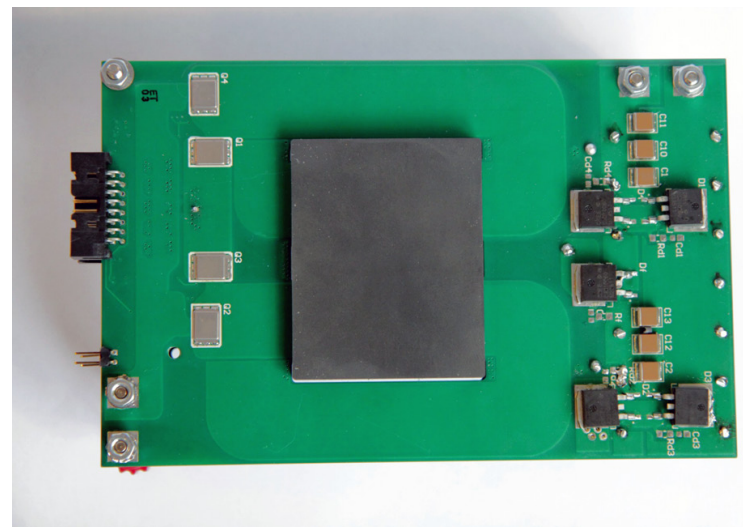

Fig. 16. Parallel primary $1600 \mathrm{~W}$ prototype underside without heat sink DirectFet IRF7759L2T MOSFETs are visible on the left, the ELP64 core in the middle, and C3D10060G SiC diodes including the flyback diode $D_{f}$ on the right.

optimized for high efficiency but rather for fulfilling the functional requirements of start-up without affecting normal boost mode operation efficiency. Alternative applications of the method may focus on wide-range high-efficiency by employing soft-switching or regenerative snubbing, potentially making the integration method suitable for diverse applications such as Power Factor Correction and single stage inverters.

\section{REFERENCES}

[1] M. Nymand, R. Tranberg, M. E. Madsen, U. K. Madawala, and M. A. E. Andersen, "What is the best converter for low voltage fuel cell applications- a buck or boost?" Proc. IEEE Ind. Electron. Soc. Conf., pp. 962-970, 2009.

[2] M. Nymand and M. A. E. Andersen, "High-efficiency isolated boost dcdc converter for high-power low-voltage fuel-cell applications," IEEE Trans. on Ind. Electronics, vol. 57, no. 2, pp. 505-514, 2010.

[3] — , "New primary-parallel boost converter for high-power high-gain applications," in Proc. IEEE Appl. Power Electron. Conf. Expo., pp. 35-39, 2009.

[4] - "A new very-high-efficiency $\mathrm{r} 4$ converter for high-power fuel cell applications," in Proc. Int. Conf. on Power Electronics and Drive Systems, pp. 997-1001, 2009.

[5] G. K. Andersen, C. Klumpner, S. Kjaer, and F. Blaabjerg, "A new power converter for fuel cells with high system efficiency," Int. J. Electron., vol. 90, no. 11/12, pp. 737-750, 2003. 
[6] J. J. Albrecht, "Boost-buck push-pull converter for very wide input range single stage power conversion," In Proc. IEEE Appl. Power Electron. Conf. Expo., pp. 303-308, 1995.

[7] L. Zhu, K. Wang, F. C. Lee, and J.-S. Lai., "New start-up schemes for isolated full-bridge boost converters," IEEE Trans. on Power Electron., vol. 18, pp. 946-951, 2003.

[8] T. Bascope and G. Barbi, "Isolated flyback-current-fed push-pull converter for power factor correction," In Proc. Power Elec. Spec. Conf., vol. 2, pp. 1184-1190, 1996.

[9] D. A. Filho and I. W.C.P. ad Barbi, "A comparison between two currentfed push-pull dc-dc converters - analysis, design and experimentation," in Proc. Telecom. Energy Conf., pp. 313-320, 1996.

[10] Z. Ouyang, Z. Zhang, O. C. Thomsen, M. A. E. Andersen, O. Poulsen, and T. Bjorklund., "Planar integrated magnetics design in wide input range dc-dc converter for fuel cell application," In Proc. IEEE Energy Conversion Congress and Exposition, pp. 4611-4618, 2010.

[11] Z. Ouyang, G. Sen, O. C. Thomsen, M. A. E. Andersen, and T. Bjorklund, "Fully integrated planar magnetics for primary-parallel isolated boost converter," In Proc. IEEE Appl. Power Electron. Conf. Expo., pp. 174-181, 2011. 